\title{
Early Life Stress Enhances Behavioral Vulnerability to Stress through the Activation of REST4-Mediated Gene Transcription in the Medial Prefrontal Cortex of Rodents
}

\author{
Shusaku Uchida, ${ }^{1}$ Kumiko Hara, ${ }^{1}$ Ayumi Kobayashi, ${ }^{1}$ Hiromasa Funato, ${ }^{1}$ Teruyuki Hobara, ${ }^{1}$ Koji Otsuki, ${ }^{1}$ \\ Hirotaka Yamagata, ${ }^{1}$ Bruce S. McEwen, ${ }^{2}$ and Yoshifumi Watanabe ${ }^{1}$ \\ ${ }^{1}$ Division of Neuropsychiatry, Department of Neuroscience, Yamaguchi University Graduate School of Medicine, Yamaguchi 755-8505, Japan, and \\ ${ }^{2}$ Laboratory of Neuroendocrinology, The Rockefeller University, New York, New York, 10021
}

There is growing evidence suggesting that early life events have long-term effects on the neuroendocrine and behavioral developments of rodents. However, little is known about the involvement of early life events in the susceptibility to subsequent stress exposure during adulthood. The present study characterized the effect of maternal separation, an animal model of early life adversity, on the behavioral response to repeated restraint stress in adult rats and investigated the molecular mechanism underlying behavioral vulnerability to chronic stress induced by the maternal separation. Rat pups were separated from the dams for $180 \mathrm{~min}$ per day from postnatal day 2 through 14 (HMS180 rats). We found that, as young adults, HMS180 rats showed a greater hypothalamic-pituitary-adrenal axis response to acute restraint stress than nonseparated control rats. In addition, repeatedly restrained HMS180 rats showed increased depressionlike behavior and an anhedonic response compared with nonrestrained HMS180 rats. Furthermore, HMS180 rats showed increased expression of REST4, a neuron-specific splicing variant of the transcriptional repressor REST (repressor element-1 silencing transcription factor), and a variety of REST target gene mRNAs and microRNAs in the medial prefrontal cortex (mPFC). Finally, REST4 overexpression in the mPFC of neonatal mice via polyethyleneimine-mediated gene transfer enhanced the expression of its target genes as well as behavioral vulnerability to repeated restraint stress. In contrast, REST4 overexpression in the MPFC of adult mice did not affect depression-like behaviors after repeated stress exposure. These results suggest that the activation of REST4-mediated gene regulation in the mPFC during postnatal development is involved in stress vulnerability.

\section{Introduction}

Early life adversity is one of the most prominent environmental factors associated with an increased risk of developing mood and anxiety disorders (Heim and Nemeroff, 2001; Gross and Hen, 2004). A growing body of evidence suggests that early environmental factors can affect long-term behavioral and neuroendocrine consequences in rodents (Liu et al., 1997, 2000; Meaney, 2001; Francis et al., 2003). Early maternal separation is an animal model of early life adversity that modulates the development of the hypothalamic-pituitary-adrenal (HPA) axis together with subsequent brain functions and emotional behaviors during adulthood (Plotsky and Meaney, 1993; Liu et al., 2000; Francis et al., 2002; Weaver et al., 2004; Murgatroyd et al., 2009).

Received March 20, 2010; revised July 23, 2010; accepted July 30, 2010.

This study was supported in part by a Grant-in-Aid for Scientific Research from the Japanese Ministry of Education, Culture, Sports, Science and Technology and a grant for Research on Psychiatric and Neurological Diseases and Mental Health from the Japanese Ministry of Health, Labor and Welfare. We thank Drs. Yoshihide Tsujimoto, Koh Shinoda, Shoji Nakamura, Koji Matsuo, Yoichi Mizukami, and Tomoaki Murata for technical advice.

The authors declare that they have no competing financial interests.

Correspondence should be addressed to either Dr. Shusaku Uchida or Dr. Yoshifumi Watanabe, Division of Neuropsychiatry, Department of Neuroscience, Yamaguchi University Graduate School of Medicine, 1-1-1 Minamikogushi, Ube, Yamaguchi 755-8505, Japan. E-mail: s-uchida@yamaguchi-u.ac.jp or yoshiwat@yamaguchi-u.ac.jp. DOI:10.1523/JNEUROSCI.1436-10.2010

Copyright $\odot 2010$ the authors $\quad 0270-6474 / 10 / 3015007-12 \$ 15.00 / 0$
The medial prefrontal cortex ( $\mathrm{mPFC}$ ) plays an important role in modulating the neural circuitry that mediates the HPA axis and emotional responses to stress (Arnsten, 2009; Ulrich-Lai and Herman, 2009). Early postnatal life is a critical period for the development of the mPFC (Benes et al., 2000). Several lines of evidence show that early life stress results in abnormally high synaptic density (Ovtscharoff and Braun, 2001), decreased dendritic length (Pascual et al., 2007), attenuated basal neuronal activity (Stevenson et al., 2008), and increased serotonin (5-HT) 1A receptor-mediated outward currents during postnatal development (Goodfellow et al., 2009) within the mPFC. To date however, the molecular mechanisms underlying these plastic changes in the $\mathrm{mPFC}$ remain to be fully elucidated.

It has been suggested that neuronal activity regulates a complex program of gene expression involved in structural and functional plasticity (Flavell and Greenberg, 2008). There is increasing evidence demonstrating that aberrant transcriptional regulation is one of the key components of the pathogenesis of several neuropsychiatric disorders, including mood disorders (Duman and Monteggia, 2006; Tsankova et al., 2007). Repressor element-1 silencing transcription factor (REST), also known as "neuron restrictive silencing factor," is a transcription factor that binds to the repressor element-1 (RE-1) conserved consensus sequence, allowing the transcriptional repression of RE-1-containing target genes, most of which are expressed in 
neurons (Chong et al., 1995; Schoenherr and Anderson, 1995; Tapia-Ramírez et al., 1997). Of particular note, genes encoding corticotropin releasing hormone $(\mathrm{CRH})$, brain-derived neurotrophic factor (BDNF), and 5-HT1A have RE-1 sites within their promoter regions (Otto et al., 2007), and their expressions are altered by early life stress (Francis et al., 2002; Roceri et al., 2002; Lippmann et al., 2007; Goodfellow et al., 2009). However, there is no direct evidence demonstrating a role of RE-1-mediated gene regulation in the development of behavioral vulnerability to chronic stress.

In the present study, we aimed to examine the behavioral vulnerability to chronic stress and to clarify the molecular mechanism underlying the development of stress vulnerability in early maternally separated rats. We first assessed the neuroendocrine and behavioral consequences of maternal separation on subsequent exposure to repeated restraint stress during adulthood. We then investigated the role of RE-1-mediated gene regulation in the $\mathrm{mPFC}$ on the development of stress vulnerability.

\section{Materials and Methods}

Animals and maternal separation. Timed-pregnant Sprague Dawley female rats (Japan SLC Inc.) arrived at the animal facility when they were 13-14 d pregnant. Females were individually housed and maintained under standard laboratory conditions (relative humidity $45 \pm 5 \%$, light/ dark cycle $12 \mathrm{~h} / 12 \mathrm{~h}$, food and water ad libitum). The maternal separation procedures used in this study have been described previously (Plotsky and Meaney, 1993; Ladd et al., 2004; Lippmann et al., 2007). The pups were randomly assigned to one of three rearing conditions: (1) animal facility rearing (AFR) - handling of pups twice a week during routine cage changes, (2) HMS15-daily 15 min period of maternal separation from postnatal day 2 (P2) to P14 inclusive, (3) HMS180 — daily $180 \mathrm{~min}$ period of maternal separation from P2 to P14 inclusive. Protocols involving manipulation of the pups took place between 9:00 A.M. and 12:00 noon daily. During separation, each dam was removed from its maternity cage and placed into an adjacent identical cage until the end of the separation period. Pups were then removed as complete foster litters from the nest, placed into an empty cage and transferred to an incubator in an adjacent room. The incubator was maintained at $32 \pm 0.5^{\circ} \mathrm{C}$ from $\mathrm{P} 2$ to $\mathrm{P} 5$ and $30 \pm 0.5^{\circ} \mathrm{C}$ from $\mathrm{P} 6$ to $\mathrm{P} 14$. At the end of the separation period, foster litters were returned to their maternity cages, followed by reunion with the dams. Pups were weaned at P21-P23 and housed in groups of three to four of the same gender until the start of the experiments. Timed-pregnant C57BL/6J female and male (7 weeks old) mice were obtained from Charles River. Females were individually housed and maintained under standard laboratory conditions (relative humidity $45 \pm 5 \%$, light/dark cycle $12 \mathrm{~h} / 12 \mathrm{~h}$, food and water ad libitum). Adult male mice were housed in cages of four or five. All experimental procedures were performed according to the Guidelines for Animal Care and Use at Yamaguchi University School of Medicine. Experimental protocols were approved by the Committee on the Ethics of Animal Experiments at Yamaguchi University School of Medicine.

Repeated restraint stress procedure. Adult rats ( 8 weeks old) were weighed and individually subjected to restraint stress ( $2 \mathrm{~h}$ per day) for 14 consecutive days by placing them into wire mesh restrainers secured at the head and tail ends with clips as previously reported (Uchida et al., 2008). Mice ( 8 weeks old) were subjected to restraint stress ( $2 \mathrm{~h}$ per day) in a $50 \mathrm{ml}$ plastic centrifuge tube for 14 consecutive days. Nonrepeated restrained animals (NRRS) were left in their home cage and were handled for 14 consecutive days during weighing.

Corticosterone assay. Adult animals from acute restrained groups were killed by decapitation at 30 and $60 \mathrm{~min}$ after the initiation of a $30 \mathrm{~min}$ period of restraint stress. Nonrestrained controls were rapidly removed from their cages and decapitated. Trunk blood was collected in heparinized tubes and plasma was separated by centrifugation and stored at $-80^{\circ} \mathrm{C}$ for corticosterone determination. Corticosterone concentration was determined using a commercial enzyme immunoassay kit (Cayman Chemical).
Behavioral procedures. Behavioral testing was performed during the light phase of the cycle, as previously reported with some modifications (Uchida et al., 2005, 2008, 2010). All experiments were conducted blind to the treatment condition of the animal.

Sucrose preference test. Animals were habituated to drink water from two bottles for $7 \mathrm{~d}$. They were then submitted to $72 \mathrm{~h}$ of forced exposure to $1 \%$ sucrose solution to avoid neophobia. After the stress sessions, the animals were submitted to water deprivation for $16 \mathrm{~h}$ before performing the sucrose preference test. Two preweighed bottles, one containing tap water and the other containing $1 \%$ sucrose solution, were presented to each animal for $4 \mathrm{~h}$. The position of the water and sucrose bottles (left or right) was switched every $2 \mathrm{~h}$. The bottles were weighed again and the weight difference was considered to be the animal intake from each bottle. The sum of water and sucrose intake was defined as total intake and the sucrose preference was expressed as the percentage of sucrose intake from the total intake.

Forced swimming test. Animals were placed in a water tank (for rats; 50 $\mathrm{cm}$ high by $30 \mathrm{~cm}$ in diameter; filled with $23^{\circ} \mathrm{C}$ water at a depth of $30 \mathrm{~cm}$, for mice; $25 \mathrm{~cm}$ high by $15 \mathrm{~cm}$ in diameter; filled with $23^{\circ} \mathrm{C}$ water at a depth of $15 \mathrm{~cm}$ ) for $5 \mathrm{~min}$ and the duration of floating (i.e., the time during which the animal made only the small movements necessary to keep its head above water) and the latency to first immobility were scored. Animals were then dried and returned to the home cage.

Novelty-suppressed feeding test. Animals were weighed (body weight A) and singly housed after the termination of the final restraint stress session on the 14th day, and food pellets were removed from their cages. Water remained available ad libitum. Twenty-four hours after food removal, animals were weighed (body weight B) and transferred to a clean holding cage in the testing room. The testing apparatus consisted of a circular arena (for rats; $60 \mathrm{~cm}$ in diameter) or a square open field (for mice; $30 \mathrm{~cm}$ long $\times 30 \mathrm{~cm}$ wide $\times 20 \mathrm{~cm}$ high). A piece of chow was placed in the center of the testing apparatus. Each subject was placed in a corner of the testing apparatus and the latency to the first feeding episode was recorded for $5 \mathrm{~min}$. After the test, the animal was returned to the home cage with food pellets and the amount of food consumed was measured for $60 \mathrm{~min}$. The percentage loss of body weight was estimated by: (body weight B)/ (body weight A) $\times 100$.

Real-time PCR and Northern blotting. Total RNA from dissected tissues or cells was extracted using the mirVana miRNA isolation kit (Ambion) and treated with DNase (DNA-free kit, Ambion). The quality of RNA $\left(A_{260} / A_{280}\right)$ was $1.8-2.0$ for all RNA preparations. One microgram of total RNA was used for cDNA synthesis using the QuantiTect Reverse Transcription kit (Qiagen). The primer mix of this kit contains oligo-dT and random primers to ensure cDNA synthesis from all regions of RNA transcripts. The cDNA was stored at $-80^{\circ} \mathrm{C}$ until use. Real-time PCR was performed in the Applied Biosystems 7300 Fast Real-Time PCR System with SYBR Green PCR Master Mix according to the manufacturer's protocol. PCR conditions were $15 \mathrm{~min}$ at $95^{\circ} \mathrm{C}, 45$ cycles of $15 \mathrm{~s}$ at $95^{\circ} \mathrm{C}$ and $30 \mathrm{~s}$ at $60^{\circ} \mathrm{C}$. Amplification of a single PCR product was confirmed by monitoring the dissociation curve and electrophoresis on $1.2 \%$ agarose gels stained with ethidium bromide. Amplification curves were visually inspected to set a suitable baseline range and threshold level. The relative quantification method was used for quantifying the amounts of target molecules according to the manufacturer's protocol, in which the ratio between the amount of target molecule and a reference molecule within the same sample was calculated. All measurements were performed in triplicate. Levels of Gapdh mRNA or U6 snRNA were used to normalize the relative expression level of target mRNAs and pre-miRNAs, respectively. When a significant difference was observed between experimental groups, the data were confirmed by normalizing other internal controls of $18 \mathrm{~S}$ rRNA and 5S rRNA for mRNAs and pre-miRNAs levels, respectively. All data shown are normalized to Gapdh or U6. Gapdh- and U6normalized data were very similar to the $18 \mathrm{~S}$ rRNA- and $5 S$ rRNAnormalized data, respectively. The sequences of PCR primers used are described in supplemental Table S1, available at www.jneurosci.org as supplemental material. For miRNA Northern blotting, $20 \mu \mathrm{g}$ of total RNA was separated on a $15 \%$ denaturing polyacrylamide gel. The total RNA was transferred onto Hybond $\mathrm{N}+$ membranes (GE Healthcare Biosciences), UV crosslinked, baked for $60 \mathrm{~min}$ at $80^{\circ} \mathrm{C}$ and hybridized using 
ULTRAhyb-Oligo buffer (Ambion) according to the manufacturer's protocol. Oligonucleotides complementary to mature miRNAs and ${ }^{32} \mathrm{P}$-end-labeled with $\mathrm{T} 4$ kinase (Promega), were used as probes. Probe sequences are described in supplemental Table S2, available at www.jneurosci.org as supplemental material. Levels of ribosomal RNA were visualized on gels stained with ethidium bromide. A U6 snRNA probe was applied to normalize the relative miRNA expression levels. Densitometric analysis was performed using Inquiry software (Neuroscience Inc.).

Protein extraction and Western blotting. Western blotting was performed as previously described (Uchida et al., 2006). The mPFC tissues were pooled from $2-3$ animals. Twenty or fifty micrograms of proteins were separated on $7 \%$ or $12 \%$ Tris-acetate gels and transblotted onto polyvinylidene difluoride membranes (GE Healthcare Biosciences). The membranes were incubated with antibodies directed against REST-C (1:500; Millipore), actin (1:2000; Sigma), histone-H3 (1:2000; Millipore), or hemagglutinin (HA)-tag (1:10,000; Abcam). A rabbit polyclonal antibody to REST4 was prepared against the C-terminal epitope SECDLVG and used in a dilution of 1:1000. After incubation with an appropriate horseradish peroxidase-conjugated secondary antibody (Cell Signaling Technology), the blots were developed with an ECL-Plus detection kit (GE Healthcare Biosciences). Densitometric analysis was performed using Inquiry software (Neuroscience Inc.).

Immunohistochemistry. Rats were deeply anesthetized with sodium pentobarbital ( $50 \mathrm{mg} / \mathrm{kg}$, i.p.), and transcardially perfused with $4 \%$ paraformaldehyde in $1 \times$ PBS. Brains were postfixed overnight in $4 \%$ paraformaldehyde, cryoprotected in $30 \%$ sucrose in $1 \times$ PBS, and sectioned $(30 \mu \mathrm{m})$ using a cryostat. Double immunocytochemistry was performed on free-floating sections. Antibodies included rabbit anti-REST4 (1:500) and mouse anti-neuronal nuclei (NeuN; 1:1000; Millipore Bioscience Research Reagents) or mouse anti-glial fibrillary acidic protein (GFAP; 1:1000; Millipore Bioscience Research Reagents). Antibody binding was visualized with anti-rabbit IgG conjugated to Alexa Fluor 488 or antimouse IgG conjugated to Alexa Fluor 568 (1:500; Invitrogen). Images were acquired with an LSM 510 META laser confocal microscope with multichannel excitation and detection options using optimal factory recommended filter configurations to minimize spectral bleed-through (Zeiss). The colocalization of markers was analyzed using ZEN2008 software (Zeiss).

Generation of DNA constructs. Full-length Rest4 (GenBank accession no. DQ644039) and Rest (GenBank accession no. NM_005612) cDNAs were amplified by PCR and cloned into the pEGFP-C1 vector (Clontech). The expression vectors pNLS-EGFP were kindly provided by Dr. Y. Tsujimoto (Osaka University Medical School, Osaka, Japan). The expression vectors, pcDNA3-REST4 and pcDNA3-REST were constructed by inserting the open reading frame of Rest 4 and Rest, respectively, with the Kozak and HA-tag sequences followed by an initiation codon into the pcDNA3 vector (Invitrogen). The control expression vectors, pcDNA3-EGFP and pcDNA3-NLS-EGFP were constructed by inserting the open reading frame of EGFP or NLS-EGFP from $p E G F P-C 1$ and pNLS-EGFP vectors, respectively, with the Kozak sequence followed by an initiation codon into the pcDNA3 vector.

Cell culture, transfection, and imaging. The Neuro2a cell line was obtained from Health Science Research Resources Bank (Osaka, Japan) and maintained in DMEM supplemented with 10\% fetal bovine serum, $1 \%$ sodium pyruvate, $100 \mathrm{U} / \mathrm{ml}$ penicillin, $100 \mu \mathrm{g} / \mathrm{ml}$ streptomycin, and 2 $\mathrm{mm}$ L-glutamine at $37^{\circ} \mathrm{C}$ in $5 \% \mathrm{CO}_{2}$. For subcellular fractionation, Neuro2a cells were transiently transfected with the pcDNA3-REST4 plasmids; $24 \mathrm{~h}$ later, the cells were washed with ice-cold PBS, and then lysed in hypotonic lysis buffer (HLB) consisting of 20 mM HEPES pH 7.4, 10 mM $\beta$-glycerophosphate, $1 \mathrm{~mm}$ EDTA, $1 \mathrm{~mm} \mathrm{Na-orthovanadate,} 2 \mathrm{~mm}$ $\mathrm{MgCl}$, 1 mM EGTA, 1 mM DTT, and complete protease inhibitor cocktail (Roche Diagnostics). Cells were homogenized by passing them through a 26 gauge needle 10 times. The homogenate was centrifuged at $500 \times g$ for $10 \mathrm{~min}$ at $4^{\circ} \mathrm{C}$. The supernatant was used as the cytoplasmic fraction. The nuclear pellet was resuspended in HLB containing $0.3 \%$ NP-40 and vortexed for $10 \mathrm{~s}$ followed by centrifugation at $500 \times g$ for 10 min. The pellet was resuspended in $0.5 \mathrm{ml}$ of HLB containing $0.05 \%$ $\mathrm{NP}-40$ and $10 \%$ glycerol. This suspension was passed through a 26 gauge needle 3 times and layered over $1 \mathrm{ml}$ of HLB supplemented with a $45 \%$ sucrose cushion. After centrifugation at $1600 \times g$ for $30 \mathrm{~min}$, the pellet containing nuclei was washed once with HLB containing $10 \%$ glycerol and examined under a light microscope to check for the purity of the nuclei; pure nuclei were devoid of membrane contamination and other subcellular organelles. The isolated nuclei preparations were solubilized using HLB containing $1 \%$ SDS and boiling for $5 \mathrm{~min}$ and then sonicated for $3 \mathrm{~s}$. After centrifugation at $14,000 \times g$ for $10 \mathrm{~min}$, the supernatant was used as the nuclear fraction. To analyze the subcellular localization of REST and REST4, Neuro2a cells were transiently transfected with the pEGFP-REST, pEGFP-REST4 or control pEGFP-C1 plasmids $(2 \mu \mathrm{g} /$ well) in $35 \mathrm{~mm}$ dishes using Lipofectamine 2000 (Invitrogen). Twentyfour hours after the transfection, EGFP fluorescence was acquired using a Biozero BZ8000 microscope (Keyence), and images were analyzed using BZ-II Analyzer software (Keyence).

In vivo plasmid transfection. Plasmid DNA-polyethyleneimine (PEI) complexes were prepared according to the instructions of the manufacturer (in vivo-jetPEI; PolyPlus Transfection). In brief, pcDNA3-REST4, pcDNA3-EGFP, or pcDNA3-NLS-EGFP plasmid DNA $(20 \mu \mathrm{g})$ was diluted in a sterile solution of $5 \%$ glucose to a final volume of $16.8 \mu \mathrm{l}$ and complexed with $3.2 \mu \mathrm{l}$ of linear PEI. The pups at P6-P7 were cryoanesthetized on ice for 5-10 min, and placed in a stereotaxic frame (Narishige). A dot was drawn on the skin surface at the insertion point with a fine felt-tipped marker. For injections into the mPFC region, the insertion point of the injection needle ( 30 gauge) was $0.3 \mathrm{~mm}$ lateral to the superior sagittal sinus and $3.5 \mathrm{~mm}$ rostral to lambda. The needle was inserted to a depth of $1.6 \mathrm{~mm}$ from the surface of the skin. Five hundred nanoliters of PEI-plasmid complexes were injected using a $5 \mu$ l Hamilton syringe. After a wait of $5 \mathrm{~min}$, the needle was slowly withdrawn. Accuracy of the coordinates was determined in pilot experiments in which methylene blue dye was infused in place of the PEI-DNA complex, and brains were sliced to display the site of the dye. The pups were then placed on a heating pad with their original nesting material for 3-5 min and returned to their mother for further recovery. Three days after surgery, successful transduction of foreign genes in the mPFC region was confirmed by immunohistochemistry and Western blotting for EGFP (rabbit antiGFP; Invitrogen) or HA (rabbit anti-HA; Abcam), respectively. On P21, mice were weaned and placed three to four per cage, combining control and REST4-injected mice together.

Adeno-associated virus (AAV)-mediated gene transfer. The plasmid DNA pAAV-MCS (CMV promoter, Stratagene) carrying HA-REST4 or EGFP cDNA was constructed from pcDNA3-HA-REST4 and pcDNA3EGFP plasmids, respectively. The plasmid DNA pAAV-EGFP or pAAVHA-REST4 was cotransfected with plasmids pHelper and pAAV-RC to HEK293 cells using a standard calcium phosphate method. After $60 \mathrm{~h}$, the cells were harvested and crude recombinant AAV (rAAV) vector solutions were obtained by repeated freeze/thaw cycles. Virus particles were purified and concentrated using a ViraBind AAV Purification Kit (Cell Biolabs Inc.), according to the manufacturer's protocol. The genomic titer of each virus $\left(\mathrm{rAAV}-\mathrm{EGFP}=5.6 \times 10^{12}\right.$ and $\mathrm{rAAV}$ REST4 $=2.7 \times 10^{12}$ viral genomes $/ \mathrm{ml}$ ) was determined by quantitative real-time PCR. For virus injection, mice were anesthetized with sodium pentobarbital (50 mg/kg i.p.) and placed in a stereotaxic frame. The skull was exposed, and a small portion of the skull over the mPFC was removed bilaterally with a dental drill. Subsequently, rAAV vector dissolved in physiological saline $(0.5 \mu \mathrm{l})$ was injected bilaterally into the $\mathrm{mPFC}(+1.7$ $\mathrm{mm}$ anteroposterior, $\pm 0.5 \mathrm{~mm}$ mediolateral, $-1.5 \mathrm{~mm}$ dorsoventral) at rate of $0.1 \mu \mathrm{l} / \mathrm{min}$. After a wait of $5 \mathrm{~min}$, the needle was slowly withdrawn. Mice were allowed to recover for 2 weeks after surgery and were subjected to restraint stress ( $2 \mathrm{~h}$ per day) for 14 consecutive days, as described above. After the end of behavioral experiments, successful transductions of EGFP and HA-REST4 in the mPFC region were confirmed by immunohistochemistry and Western blotting for GFP and HA, respectively.

Statistical analysis. Analysis of the corticosterone data was performed using two-way ANOVA, with postnatal manipulation (AFR, HMS15, HMS180) and time point (0,30, and $60 \mathrm{~min})$ as fixed factors. Analyses of the behavioral data were performed using two-way ANOVA, with postnatal manipulation (AFR, HMS15, and HMS180, PEI/Rest4 and PEI/EgfP and/or PEI/nls-Egfp, or AAV-EGFP and AAV-REST4) and stress expo- 
A

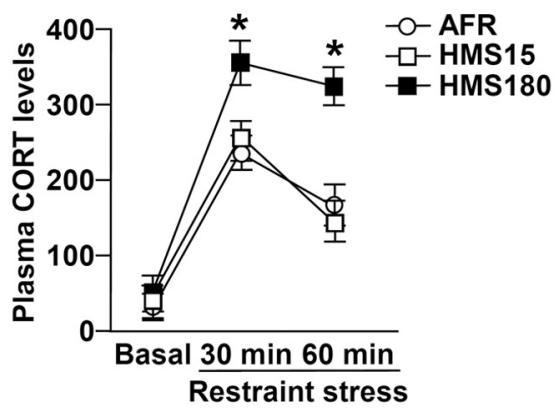

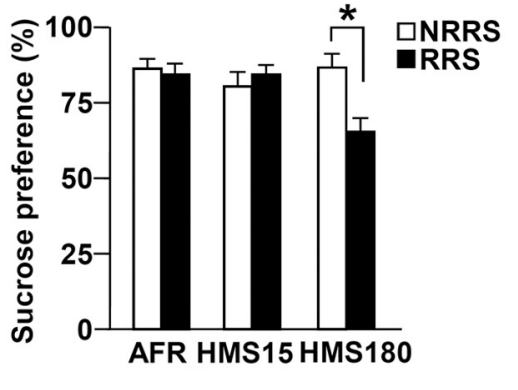

C

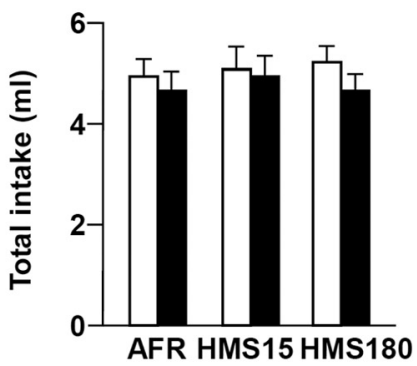

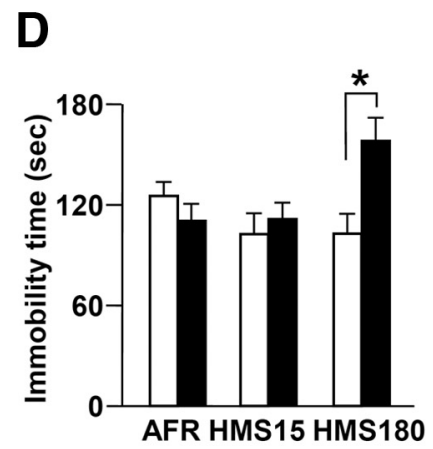

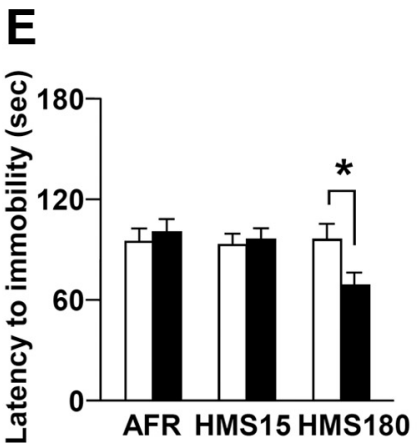

$\mathbf{F}$

G
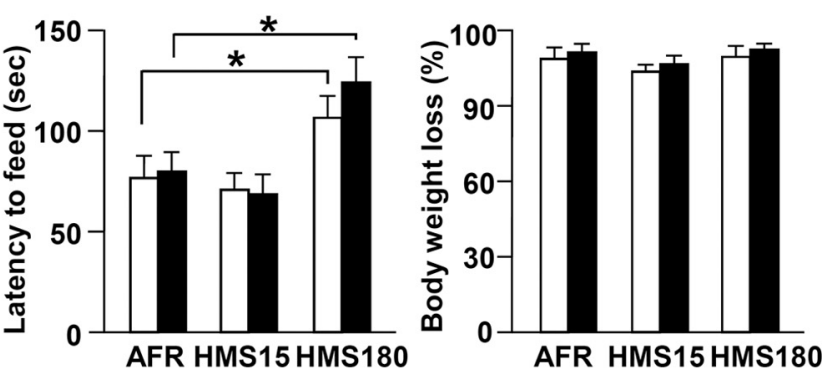

Figure 1. Maternal separation increases stress vulnerability in adults. A, Plasma corticosterone (CORT) levels in AFR, HMS15, and HMS180 rats before and 30 and 60 min after the initiation of a 30 min acute restraint stress $\left(n=6-8\right.$ for each group). HMS180 rats showed greater plasma CORT levels in response to restraint stress compared with the AFR and HMS15 rats. ${ }^{*} p<0.05 . B, C$, Bar graphs showing sucrose preference $(\boldsymbol{B})$ and total fluid intake $(\boldsymbol{C})$ in the sucrose preference test in AFR, HMS15, and HMS180 rats ( $n=12-14$ for each group) after the $14^{\text {th }}$ repeated restraint stress sessions (RRS) or nonrepeated restraint stress (NRRS). HMS180 rats subjected to RRS showed significantly deceased sucrose preference compared with the nonrestrained HMS180 rats. ${ }^{*} p<0.05$. $\boldsymbol{D}, \boldsymbol{E}$, Bar graphs showing the immobility time $(\boldsymbol{D})$ and latency to immobility $(\boldsymbol{E})$ in AFR, HMS15, and HMS180 rats subjected to a forced swim test $(n=12-14$ for each group) after the RRS or NRRS. HMS180 rats subjected to RRS showed significantly increased immobility time (D) and decreased latency to immobility $(\boldsymbol{E})$ compared with the nonrestrained HMS180 rats. ${ }^{*} p<0.05$. $\boldsymbol{F}, \boldsymbol{G}$, Bar graphs showing latency to feed $(\boldsymbol{F})$ and percentage body weight loss $(\boldsymbol{G})$ in AFR, HMS15, and HMS180 rats subjected to a novelty-suppressed feeding test $(n=12-14$ for each group) after the RRS or NRRS. ${ }^{*} p<0.05$.

sure (nonrestraint, repeated restraint) as fixed factors. Analyses of the gene expression data were performed using a one-way ANOVA. Significant effects were followed up with Bonferroni's post hoc tests. Unpaired $t$ tests were used for two-group comparisons. In all cases, $P$-values were two-tailed, and differences were considered to be statistically significant for $p<0.05$. Data are presented as means \pm SEM.

\section{Results}

Maternally separated rats show vulnerability to restraint stress

Dysregulation of the HPA axis is associated with stress vulnerability (de Kloet et al., 2005). To examine HPA axis function in the maternally separated HMS180 rats, we measured plasma corticosterone levels following acute restraint stress (Fig. 1A). There were significant effects of postnatal manipulation $\left(F_{(2,50)}=\right.$ 21.97, $p<0.01)$ over time $\left(F_{(2,50)}=56.18, p<0.01\right)$ with a significant interaction between the two factors $\left(F_{(4,50)}=4.37, p<\right.$ 0.05). At 30 and $60 \mathrm{~min}$ after the initiation of restraint stress, plasma corticosterone levels were significantly greater in the HMS180 rats than in both the AFR and HMS15 rats (post hoc, $p<0.01$ ). These results concur with previous reports (Francis et al., 2002; Lippmann et al., 2007; Murgatroyd et al., 2009), and suggest that maternal separation increases the HPA axis response to stress.

We next examined the behavioral responses to repeated restraint stress. Adult AFR, HMS15, and HMS180 rats underwent restraint stress ( $2 \mathrm{~h}$ per day) for 14 consecutive days; we then assessed their anxiety- and depression-like behaviors. Anhedonia, diminished interest or pleasure, is one of the core symptoms of major depression (American Psychiatric Association, 1994).
To examine whether maternally separated rats with or without additional repeated restraint stress were in an anhedonic state, we conducted the sucrose preference test (Fig. $1 B$ ). There were significant effects of postnatal manipulation $\left(F_{(2,73)}=4.97, p<\right.$ $0.05)$, restraint stress exposure $\left(F_{(1,73)}=6.23, p<0.01\right)$ and their interaction $\left(F_{(2,73)}=4.44, p<0.05\right)$ on the sucrose preference. Maternal separation did not affect the sucrose preference of nonrestrained animals, whereas the sucrose preference of HMS180 rats following repeated restraint stress was significantly decreased compared with that of nonrestrained AFR ( post hoc, $p<0.01$ ) and HMS180 rats ( $p o s t h o c, p<0.01$ ). Total fluid consumptions were stable and were not significantly affected by any treatment (Fig. 1C).

We then subjected animals to the acute, forced swim test, which uses increased immobility time as an index of depressionlike behavior in rodents (Porsolt et al., 1977) (Fig. 1D). There were significant effects of postnatal manipulation $\left(F_{(2,73)}=4.15\right.$, $p<0.05)$ and the interaction of postnatal manipulation $\times$ restraint stress exposure $\left(F_{(2,73)}=4.14, p<0.05\right)$ on the immobility time. Maternal separation did not affect the immobility time in nonrestrained animals, whereas HMS180 rats following repeated restraint stress showed a significant increase in immobility time compared with that of both nonrestrained AFR ( post hoc, $p<0.05$ ) and HMS180 rats (post hoc, $p<0.05$ ). In addition to examining total immobility time, we also assessed the latency to first episode of immobility (Fig. $1 E$ ). Two-way ANOVA revealed that there was significant effect of the interaction of postnatal manipulation $\times$ restraint stress exposure $\left(F_{(2,73)}=4.28, p<\right.$ $0.05)$ on the latency to immobility. The restrained HMS180 rats 

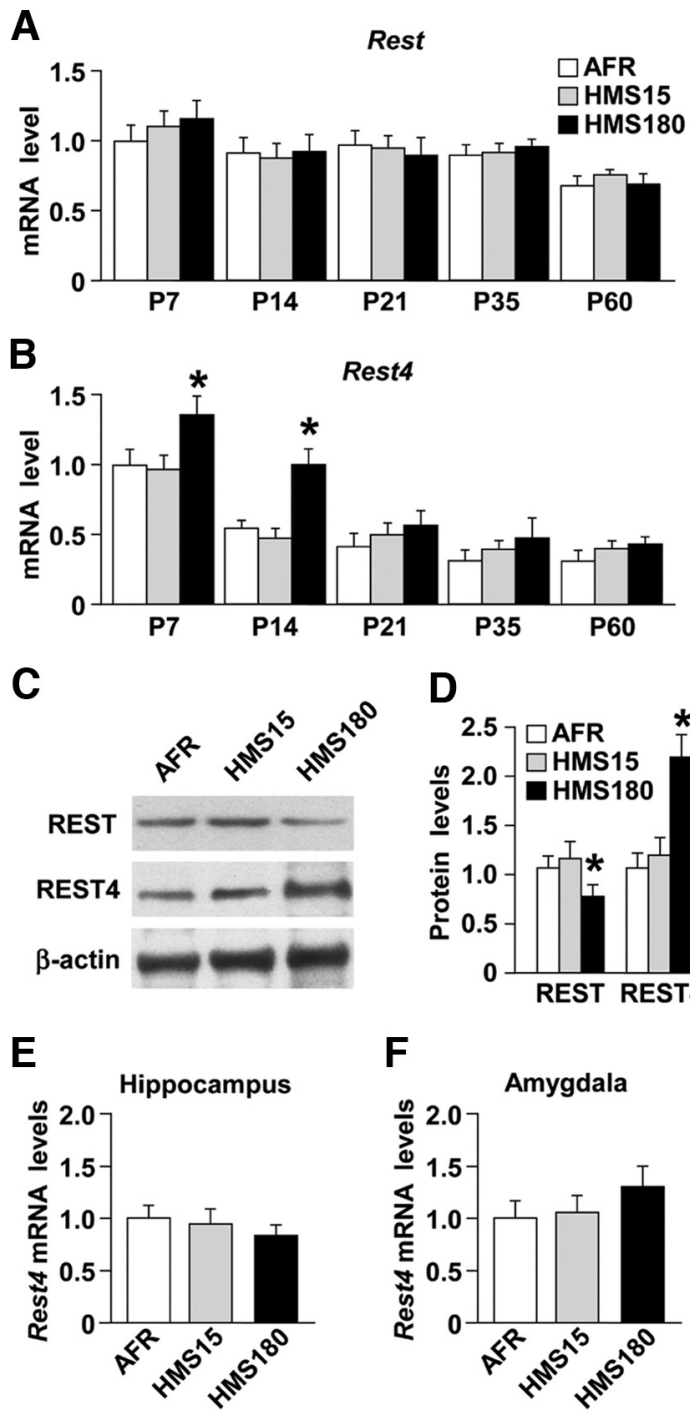

Figure 2. Maternal separation increases the REST4 expression in the MPFC of rats. $A, B, B$ ar graphs showing the mRNA expressions of Rest $(\boldsymbol{A})$ and Rest 4 ( $\boldsymbol{B})$ in the mPFC of AFR, HMS15, and HMS180 rats at P7, P14, P21, P35, and P60 quantified by quantitative (Q)-PCR ( $n=6$ for all groups). The expression of Rest $4 \mathrm{mRNA}$ was significantly increased in the HMS180 rats at $P 7$ and P14 compared with that in the age-matched HMS15 and control AFR rats $\left({ }^{*} p<0.01\right) . C, D$, The protein expressions of REST and REST 4 in the MPFC of AFR, HMS15, and HMS180 rats at P14 were quantified by Western blotting analysis ( $n=4-5$ for each group, $2-3$ pooled tissues per $n$ ). The expression of REST 4 protein was significantly increased in the HMS180 rats compared with that in the AFR and HMS15 rats ( $\left.{ }^{*} p<0.05\right) . \boldsymbol{E}$, $\boldsymbol{F}$, The mRNA expressions of Rest 4 in the hippocampus $(\boldsymbol{E})$ and the amygdala $(\boldsymbol{F})$ of AFR, HMS15, and HMS180 rats at P14 were quantified by Q-PCR ( $n=6$ for all groups). There were no significant differences in Rest 4 mRNA levels among the three groups in these brain regions.

showed a significantly shorter latency to immobility compared with that of both nonrestrained AFR (post hoc, $p<0.05$ ) and HMS180 rats ( post hoc, $p<0.05$ ).

Anxiety is frequently comorbid in patients with major depression (Zimmerman et al., 2002). To examine whether maternally separated rats with or without additional repeated restraint stress during adulthood were anxious, we conducted the noveltysuppressed feeding test (Fig. $1 F$ ). The latency to begin eating has been used as an index of anxiety behavior, because classical anxiolytic drugs decrease this latency. There were significant effects of postnatal manipulation $\left(F_{(2,73)}=13.78, p<0.01\right)$ on the latency to feed. Nonrestrained and repeatedly restrained HMS180 rats showed significantly longer latencies to begin eating than nonre-
A

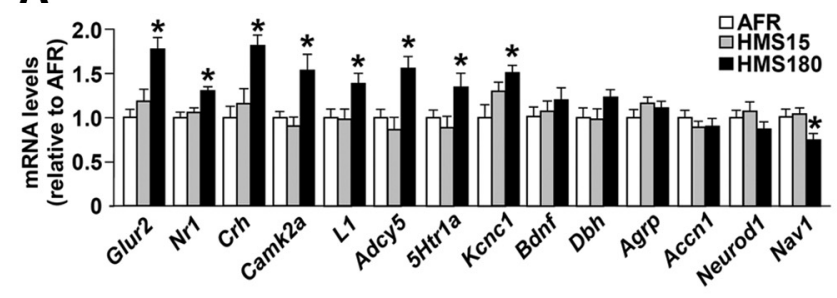

B

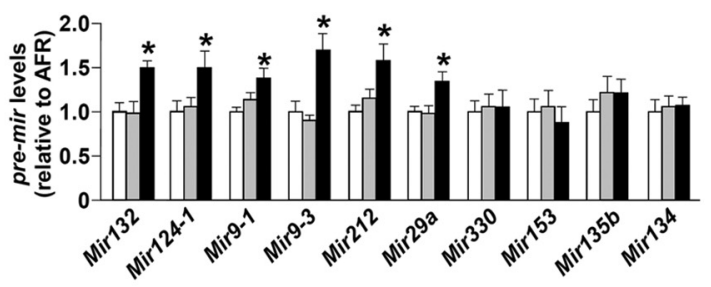

C

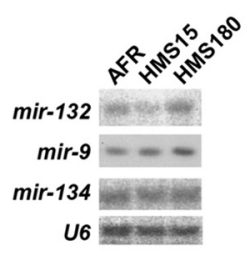

D

$\mathbf{E}$
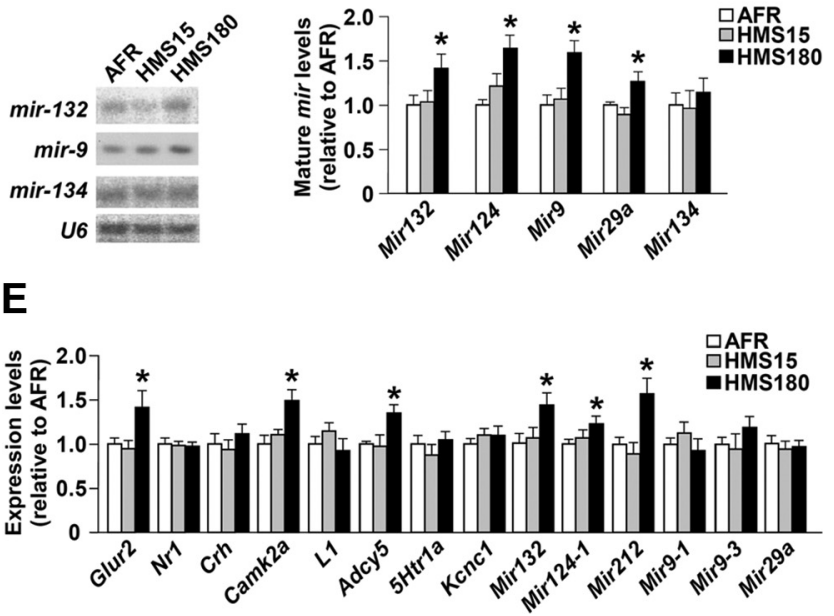

Figure 3. Expression analyses of mRNAs of RE-1-containing genes and brain-enriched premicroRNAs in the mPFC of the maternally separated rats. $\boldsymbol{A}, \boldsymbol{B}$, The expression of mRNAs $(\boldsymbol{A})$ and pre-microRNAs $(\boldsymbol{B})$ of a variety of RE-1-containing genes in the MPFC of AFR, HMS15, and HMS180 rats at P14 were quantified by Q-PCR ( $n=6$ for all groups). C, $\boldsymbol{D}$, The expression of mature microRNAs in the MPFC of AFR, HMS15, and HMS180 rats at P14 were quantified by Northern blotting analysis ( $n=5-6$ for each group). $\boldsymbol{E}$, The mRNA and pre-microRNA expression of RE-1-containing genes in the MPFC of adult AFR, HMS15, and HMS180 rats were quantified by $\mathrm{Q}-\mathrm{PCR}$ ( $n=6$ for all groups). ${ }^{*} p<0.05$.

strained AFR rats ( post hoc, $p<0.05$ ), with no differences in weight loss induced by food deprivation (Fig. 1G) or in feeding activity assessed after the end of the test (data not shown). These behavioral results suggest that maternal separation increases the risk of developing depression- and anxiety-like behaviors after subsequent repeated restraint stress during adulthood.

\section{Increased REST4 expression in the MPFC of maternally} separated rats

We next examined the molecular mechanisms underlying stress vulnerability in HMS180 rats. A recent report indicated that the transcriptional repressor REST has many target genes, including Crh, Bdnf, and 5Htrla (Otto et al., 2007), the expressions of which are altered in animals subjected to early life stress (Francis et al., 2002; Roceri et al., 2002; Lippmann et al., 2007; Goodfellow et al., 2009). To test whether the expressions of REST, as well as REST4, a splicing variant of REST, were altered by the maternal separation we examined their mRNA and protein levels (Fig. 2). Real-time PCR revealed that the expression of Rest mRNA in the 
mPFC of HMS180 rats was comparable to that of AFR and HMS15 rats during all stages of development examined $\left(F_{(14,75)}=\right.$ $1.01, p>0.05)$ (Fig. 2A). In contrast, the mRNA expression of Rest4 in HMS180 rats was significantly higher than that of AFR and HMS15 rats at P7 $\left(F_{(14,75)}=\right.$ 33.65, $p<0.01$; post hoc, $p<0.01)$ and P14 (post hoc, $p<0.01$ ) (Fig. $2 B$ ). The altered expression of Rest4 mRNA in HMS180 rats was not observed in P21, P35, and adult rats (Fig. $2 \mathrm{~B}$ ). We also examined the expression of mRNA for Rest 2 and Rest 3 isoforms in the mPFC of rats, but these expressions were quite low or nondetectable (data not shown). Western blotting revealed that the level of REST protein in the mPFC of HMS180 rats at P14 was significantly decreased compared with those of AFR and HMS15 rats $\left(F_{(2,15)}\right.$ $=4.51, p<0.05$; post hoc, $p<0.05)$, and the expression of REST4 protein was significantly increased compared with those in AFR and HMS15 rats $\left(F_{(2,15)}=8.26\right.$, $p<0.01$; post hoc, $p<0.05$ ) (Fig. $2 C, D$ ). In $\mathrm{P} 14$ rats, there were no significant differences in the levels of Rest and Rest4 mRNAs among the three groups in either the hippocampus (Rest, $F_{(2,15)}=0.86, p>$ 0.05 ; Rest $\left.4, F_{(2,15)}=0.45, p>0.05\right)$ or the amygdala $\left(\right.$ Rest, $F_{(2,15)}=0.11, p>0.05$; Rest4, $F_{(2,15)}=0.61, p>0.05$ ) (Fig. $2 E, F$; data not shown). These results suggest an aberrant RE-1-mediated gene regulation induced by the altered REST4 and/or REST expression in the MPFC of the HMS180 rats during early postnatal periods.

\section{Altered mRNA expression of \\ RE-1-containing genes in the maternally separated rats}

To test whether the expressions of RE1 -containing genes were affected in the HMS180 rats, we examined the mRNA levels of such genes in the mPFC. As shown in Figure $3 A$, the expressions of mRNAs for the AMPA glutamate receptor 2 subunit (Glur2), NMDA receptor 1 subunit (Nr1), Crh, calcium/calmodulin-dependent protein kinase II $\alpha$ (CamKII $\alpha)$, cell adhesion molecule L1 (L1), adenylate cyclase 5 (Adcy5), 5htrla, and voltage-gated potassium channel subunit Kv3.1 (Kcnc1) genes in the HMS180 rats at P14 were significantly increased compared with those in AFR and HMS15 rats. In contrast, the expression of mRNAs for the $B d n f$, dopamine $\beta$ hydroxylase $(D b h)$, agouti-related protein (Agrp), amiloridesensitive cation channel 1 (Accn1), and neurogenic differentiation 1 (Neurod1) genes in the mPFC of the HMS180 rats were comparable to those of AFR rats, and the expression of mRNA for the neuron navigator 1 (Nav1) gene was significantly decreased in HMS180 rats. We also checked the validity of our real-time PCR data using $18 \mathrm{~S}$ rRNA as an internal control. Similar to the analysis using Gapdh normalization, the expression of mRNAs for Glur2, $N r 1, C r h, C a m K I I \alpha, L 1, A d c y 5$, and 5htrla genes in the HMS180
B

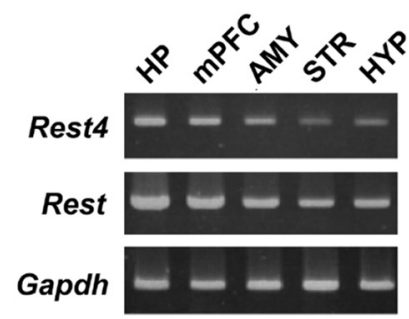

D

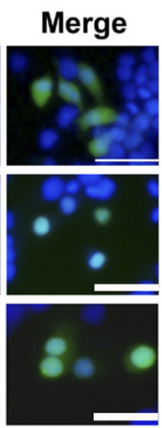

HA-REST4

Cytosol Nucleus

$\beta$-actin

Histone $\mathrm{H3}$

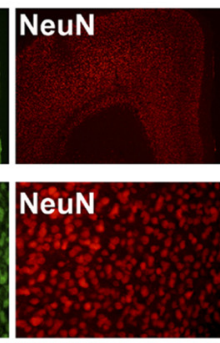

Merge

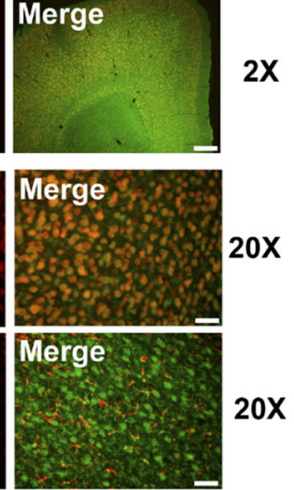

OX
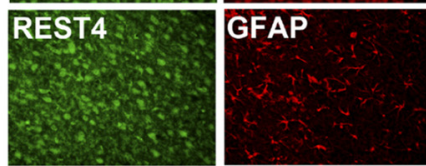

$20 x$

Figure 4. REST4 is specifically expressed in the brain and is localized in the nucleus of MPFC neurons. $\boldsymbol{A}$, Ethidium bromide stained gels of products of reverse-transcription PCR with CDNA isolated from a variety of mouse tissues showing that Rest4 is Within the brain, Rest4 mRNA was detected in the hippocampus (HP), mPFC, amygdala (AMY), striatum (STR), and hypothalamus (HYP). C, Fluorescence micrographs of Neuro2a cells transfected with either EGFP-REST4, EGFP-REST or EGFP expression vectors. Western blots of nuclear and cytosolic fractions of Neuro2a cells transfected with pCDNA3-HA-REST4 then stained with antibodagainst HA, $\beta$-actin (a marker for cytosolic protein), or histone H3 (a marker for nuclear protein). E, Anti-REST4 immunohistochemical analysis of rat coronal sections showing that REST4 immunoreactivity is colocalized with the neuronal nuclear marker NeuN in the MPFC and not with the astrocyte marker GFAP. Scale bars represent 500 and $50 \mu \mathrm{m}$ for $2 \times$ and $20 \times$, respectively.

rats were significantly increased compared with those in the AFR and HMS15 rats (supplemental Fig. S1, available at www. jneurosci.org as supplemental material).

\section{Effect of maternal separation on miRNAs expression in} the mPFC

REST regulates some of the brain-enriched microRNAs (miRNAs) (Conaco et al., 2006; Otto et al., 2007) that are thought to be involved in such neuronal functions as brain development and plasticity (Vo et al., 2005; Conaco et al., 2006; Kosik, 2006; Rajasethupathy et al., 2009). Therefore, to examine whether maternal separation affects the expression of such miRNAs in the mPFC, we measured the expression levels of 10 brain-enriched miRNAs. Real-time PCR analyses showed significantly increased expressions of preMir132, -124-1, -9-1, -9-3, -212, and -29a in HMS180 rats at P14 compared with those in AFR rats (Fig. $3 B$ ). In contrast, there were 
no significant differences among the three groups in the expression levels of pre-Mir330, $-153,-135 b$, and -134 . Northern blotting revealed that the expression levels of mature Mir132, -124, -9 , and $-29 a$ in HMS180 rats at P14 were significantly higher than those in the other groups (Fig. $3 C, D$ ), whereas the expression levels of mature Mir134 were not significantly different among the three groups. It should be noted that Mir132, -124-1, -9-1, $-9-3,-212$ and $-29 a$ all have an RE-1 site within $50 \mathrm{~kb}$ of their promoter regions (Otto et al., 2007). Thus, our data suggest that the altered expressions of mRNAs and miRNAs of RE-1containing genes in the MPFC of HMS180 rats might be due to the activation of RE-1-mediated gene transcription. We also examined the expressions of mRNA and miRNAs for some of the RE-1-containing genes in the mPFC of adult rats (P58-P60), and found increased expressions of mRNA for the Glur2, CamKII $\alpha$ and $A d c y 5$ genes and for the precursors for Mir132, -124, and -212 (Fig. 3E).

\section{Characterizations of the expression and function of REST4}

Although REST4 is a splicing variant of REST, its role in transcriptional regulation is not completely understood. Therefore we characterized the expression and function of REST4. As shown in Figure $4 A$, the expression of Rest 4 mRNA in mice was restricted to the brain, whereas that of Rest was ubiquitously expressed in a variety of tissues, including liver, spleen, lung, heart, kidney, testis, and ovary. These results concur with previous data from rat tissues (Palm et al., 1998). Within the brain, the expression of Rest4 mRNA was detected in the hippocampus, mPFC, amygdala, striatum, and hypothalamus (Fig. $4 B$ ). We next examined the subcellular localization of REST4. When we transiently transfected Neuro2a cells with an EGFP-REST4 expression vector, we detected EGFP fluorescence in the cell nuclei (Fig. 4C). Western blotting also demonstrated that REST4 was localized in the nucleus and not in the cytoplasm of the Neuro2a cells (Fig. $4 D)$. To investigate the subcellular localization of REST4 in vivo, we generated antibodies specific to the C-terminal epitopes of REST4, and performed immunohistochemistry in rat brain sections. REST4-immunofluorescence was colocalized with that for the neuronal nuclear marker NeuN, while colocalization with the astrocyte marker GFAP was very low (Fig. $4 E$ ). These results indicate that REST4 is localized in neuronal nuclei in the $\mathrm{mPFC}$, and that it may act there as a brain-specific regulator of gene transcription.

To investigate the role of REST4 in the transcriptional regulation of RE-1-containing genes in vivo, we overexpressed REST4 in the $\mathrm{mPFC}$ of neonatal mice by injecting a plasmid vector containing either the Egfp or Rest 4 cDNA using the PEI delivery system, and analyzed the expression of eight mRNAs and six pre-miRNAs, whose expressions were increased in HMS180 rats. To confirm the successful transduction of the PEI delivery system, EGFP or HA-REST4 expression plasmids complexed with PEI were injected into the $\mathrm{mPFC}$ of neonatal mice at P6. EGFPpositive cells were observed $3 \mathrm{~d}$ after the injection (Fig. $5 A$ ). In addition, Western blotting revealed the induction of exogenous REST4 (HA-REST4) in the mPFC of mice $3 \mathrm{~d}$ after the injection (Fig. 5B). We thus concluded that the foreign gene was successfully transduced in the mPFC by PEI. Using this method, we found that in the presence of the overexpression of REST4 in the mPFC of neonatal mice the mRNAs for Crh, 5 htrla, CamKIIa, Glur2, Nr1, Adcy5 (Fig. 5C), and the precursors of Mir132, Mir212, and Mir9-3 (Fig. 5D) were significantly increased. These results suggest that REST4 enhances the transcription of the some of the RE-1-containing genes in vivo. However, the expression of

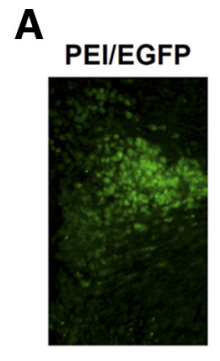

B
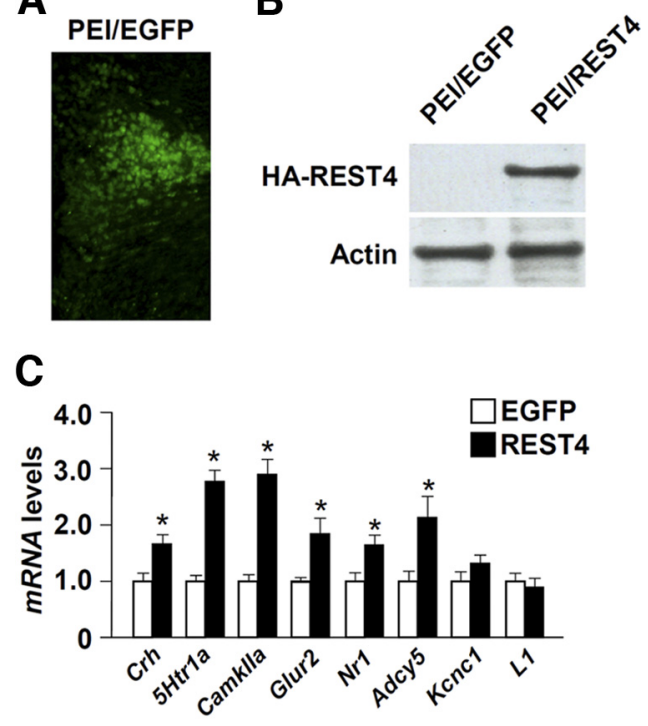

D

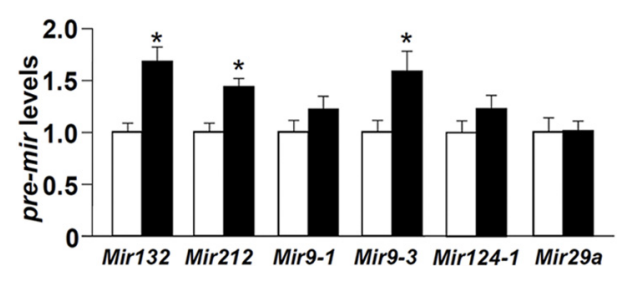

Figure 5. PEI-mediated REST4 overexpression in the MPFC of neonatal mice increases the expression of RE-1-containing genes. $\boldsymbol{A}$, Fluorescence micrograph of neonatal mouse mPFC after being injected (P6-P7) with EGFP expression plasmids complexed with PEl. Three days after the injection, EGFP fluorescence was detected in the $\mathrm{MPFC}$ region. $\boldsymbol{B}$, Western blotting with anti-HA antibody shows the transduction of HA-REST4 in the MPFC of mice $3 \mathrm{~d}$ after the injection of PEl/Rest4 complexes. $\boldsymbol{C}, \boldsymbol{D}$, Bar graphs showing Q-PCR of the levels of $\mathrm{mRNAs}(\boldsymbol{C})$ and microRNAs $(\boldsymbol{D})$ in the mPFC of mice $3 \mathrm{~d}$ after injection of either the PEl/Egfp or PEl/Rest4 complexes ( $n=6$ for each group). ${ }^{*} p<0.05$.

Kcnc1 and L1 mRNAs and pre-Mir9-1, -124-1, and -29a were not affected by the overexpression of REST4 in vivo, suggesting that REST4-mediated gene regulation is cell-type specific and/or context-dependent, and that other molecules may be involved in the regulation of the expressions of these genes in HMS180 rats.

\section{PEI-mediated REST4 gene delivery in the mPFC of neonatal} mice increases stress vulnerability

We investigated the role of postnatal REST4-mediated gene regulation in the development of stress vulnerability. The experimental design is shown in Figure 6A. We overexpressed REST4 in the $\mathrm{mPFC}$ of neonatal mice at P6-P7 by injecting a plasmid vector containing either the Rest4 or control Egfp cDNA using the PEI delivery system. To examine the neuroendocrine effect of neonatal REST4 overexpression in the adult mice, we assessed plasma corticosterone levels in response to acute restraint stress (Fig. $6 B)$. Two-way ANOVA revealed that there was significant effect of time $\left(F_{(2,35)}=23.89, p<0.01\right)$ and postnatal manipulation $\left(F_{(1,35)}=8.64, p<0.01\right)$. Plasma corticosterone levels in the REST4 overexpression mice $30 \mathrm{~min}$ after the initiation of restraint stress were significantly greater than those of the corresponding EGFP overexpression mice $(p<0.05)$. To examine the effect of neonatal REST4 overexpression on hedonic behavior after exposure to repeated restraint stress, we assessed the sucrose preference test (Fig. 6C,D). There were significant effects of postnatal manipulation $\left(F_{(1,47)}=5.24, p<0.05\right)$ and restraint stress 
exposure $\left(F_{(1,47)}=5.48, p<0.05\right)$ on the sucrose preference. The sucrose preference of REST4 overexpression mice following repeated restraint stress was significantly decreased compared with that of the nonrestrained REST4 mice ( post hoc, $p<0.05$ ) and the nonrestrained EGFP overexpression mice ( post hoc, $p<$ 0.05) (Fig. 6C). Total fluid consumptions were stable and were not significantly affected by any of the treatments (Fig. 6D). We next examined depression-like behavior using the forced swim test (Figs. $6 E, F)$. There were significant effects of postnatal manipulation $\left(F_{(1,47)}=23.31\right.$, $p<0.01)$ and the interaction of postnatal manipulation and restraint stress exposure $\left(F_{(1,47)}=6.20 ; p<0.05\right)$ on the immobility time. REST4 overexpression in the mPFC did not affect the immobility time in nonrestrained mice (Fig. $6 E$ ), but following repeated restraint stress the REST4 overexpression mice exhibited a significant increase in immobility time compared with the nonrestrained EGFP overexpression control mice (post hoc, $p<0.01$ ) (Fig. 6E). However, there was no significant effect of postnatal manipulation $\left(F_{(1,47)}=0.96, p>0.05\right)$, restraint stress exposure $\left(F_{(1,47)}=1.74, p>0.05\right)$ and their interaction $\left(F_{(1,47)}=0.28, p>\right.$ 0.05 ) on the latency to immobility (Fig. $6 F)$. To examine whether neonatal REST4 overexpression mice with or without additional repeated restraint stress during adulthood were anxious, we assessed the novelty-suppressed feeding test (Fig. $6 G, H)$. There were significant effects of postnatal manipulation $\left(F_{(1,47)}=35.26\right.$; $p<0.01)$. Nonrestrained and repeatedly restrained REST4 overexpression mice exhibited significantly longer latencies to begin eating than did the EGFP overexpression groups ( post hoc, $p<0.05$ ), with no differences in weight loss induced by food deprivation (Fig. 6G,H).

To exclude the possibility that overexpression of the nuclear gene causes behavioral changes apart from any specific effects of REST4, we also used the NLS-EGFP vectors as controls. We overexpressed either NLS-EGFP, EGFP, or REST4 in the mPFC of neonatal mice (P6-P7) using the PEI delivery system, and analyzed anxiety behavior using the noveltysuppressed feeding test during adulthood (supplemental Fig. S2, available at www.jneurosci.org as supplemental material). We found that REST4 overexpression mice showed an increased latency to feed in the novel environment compared with NLSEGFP and EGFP overexpression mice, whereas the latency to feed in the home cage and body weight loss were comparable among the groups (supplemental Fig. S2, available at www.jneurosci.org as supplemental material). Thus, our data indicate that the overexpression of REST4 in the MPFC during the neonatal period increases anxiety behavior and the behavioral vulnerability to repeated restraint stress in adulthood.
B
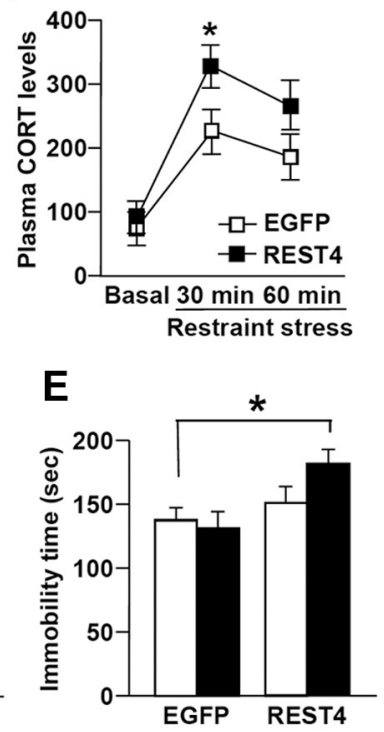

$\mathrm{H}$

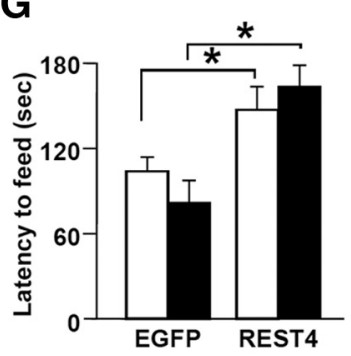

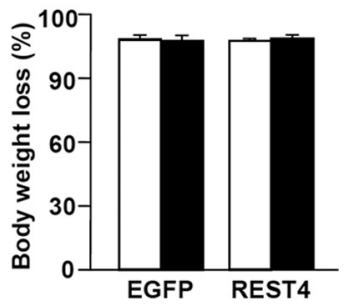

Figure 6. PEI-mediated REST4 overexpression in the MPFC of neonatal mice increases stress vulnerability. $\boldsymbol{A}$, Schematic of (N) ( $=14-16$ for each group; see Materials and Methods for details). B, Plasma corticosterone (CORT) levels before and 30 and the total intake of fluids (D). REST4 overexpression mice subjected to RRS showed significantly deceased sucrose preferenc antly increased immobility time $(\boldsymbol{E})$ but normal latency to first immobility $(\boldsymbol{F})$ compared with the nonrestrained EGFP overexpresmice $\left({ }^{*} p<0.01\right) . \mathbf{G}, \boldsymbol{H}$, Results of the novelty-suppressed feeding test after RRS or NRRS, showing the latency to feed $(\boldsymbol{G})$ and the percentage body weight loss $(\boldsymbol{H})$ in each group. REST4 overexpression mice with and without RRS showed significantly increased latencies to feed compared with corresponding EGFP overexpression mice $\left({ }^{*} p<0.05\right)$.

Viral-mediated REST4 overexpression in the MPFC of adult mice did not affect stress vulnerability

Finally, we examined whether overexpression of REST4 in the mPFC of adult mice could also enhance behavioral vulnerability to repeated restraint stress. The experimental design is shown in Figure 7A. We overexpressed REST4 and control EGFP in the mPFC of adult mice by injecting rAAV expressing REST4 or EGFP. Successful transductions of REST4 are shown in Figure 7, $B$ and $C$. Two weeks after the virus injection, mice were subjected to 2 weeks of repeated restraint stress then to behavioral assays. In the sucrose preference test (Fig. $7 D$ ), there was no significant effects of gene delivery $\left(F_{(1,46)}=0.42, p>0.05\right)$, restraint stress exposure $\left(F_{(1,46)}=0.17, p>0.05\right)$, or their interaction $\left(F_{(1,46)}=\right.$ $0.06, p>0.05)$ on sucrose preference. In the forced swim test, there were no significant effects of gene delivery $\left(F_{(1,46)}=1.84\right.$, $p>0.05)$, restraint stress exposure $\left(F_{(1,46)}=0.08, p>0.05\right)$, or 
A

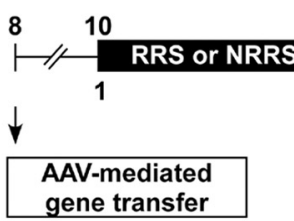

C

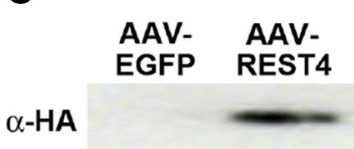

Actin

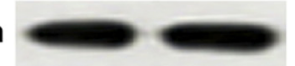

$\mathbf{F}$

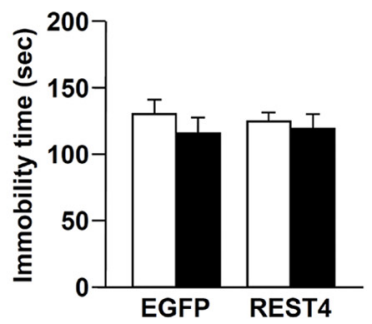

B

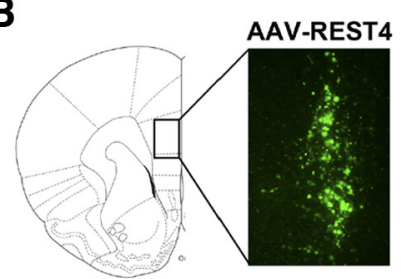

D

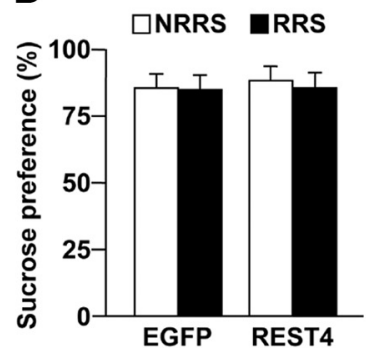

E

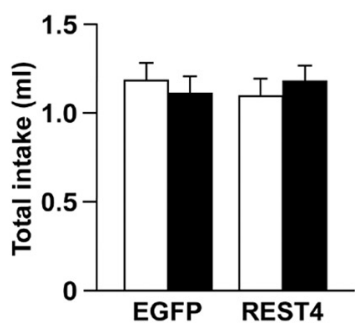

G

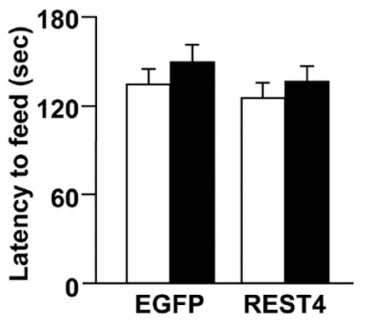

H

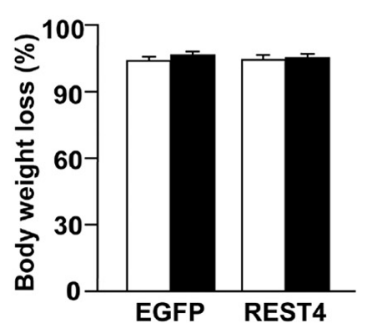

Figure 7. Effects of REST4 overexpression in the mPFC of adult mice on stress vulnerability. $\boldsymbol{A}$, Schematic of experimental design. rAAV-REST4 or control rAAV-EGFP were injected into the $\mathrm{mPFC}$ of adult mice at P56. Two weeks after the injection, mice were subjected to repeated restraint stress (RRS) or nonrepeatedly restrained stress (NRRS) for 14 consecutive days, and then assessed for anxiety- and depression-like behaviors in the sucrose preference (SPT), forced swim (FST), and novelty-suppressed feeding (NSF) tests ( $n=11-14$ for each group). $\boldsymbol{B}$, Fluorescence micrograph of adult mouse mPFC after injection of AAV-REST4. Four weeks after the injection, HA-REST4 immunofluorescence was detected in the mPFC region. $C$, Western blotting with anti-HA antibody shows the overexpression of HA-REST4 in the mPFC of mice 4 weeks after the injection of AAV-REST4.D,E, Results of the sucrose preference test after RRS or NRRS, showing sucrose preference $(\boldsymbol{D})$ and the total intake of fluids $(\boldsymbol{E})$. $\boldsymbol{F}$, Results of the forced swim test after RRS or NRRS, showing immobility time. $\boldsymbol{G}, \boldsymbol{H}$, Results of the novelty-suppressed feeding test after RRS or NRRS, showing the latency to feed $(\boldsymbol{G})$ and the percentage body weight loss $(\boldsymbol{H})$ in each group.

their interaction $\left(F_{(1,46)}=0.99, p>0.05\right)$ on the immobility time (Fig. $7 E$ ). Also in the novelty-suppressed feeding test (Fig. $7 F$ ), there were no significant effects of gene delivery $\left(F_{(1,46)}=1.28\right.$, $p>0.05)$, restraint stress exposure $\left(F_{(1,46)}=0.67, p>0.05\right)$, or their interaction $\left(F_{(1,46)}=0.12, p>0.05\right)$ on the latency to begin feeding. Thus, these behavioral data indicate that the overexpression of REST4 in the mPFC of adult mice did not affect anxiety behavior or the behavioral vulnerability to repeated restraint stress, and suggest that the network of REST4-mediated genes in the mPFC during the early postnatal period plays an important role in the development of stress vulnerability.

\section{Discussion}

In the present study, we found that maternal separation enhances stress vulnerability to repeated restraint stress exposure in adulthood. At the molecular level, maternal separation increased the expression of REST4 mRNA and protein, and that of several mRNAs and miRNAs of RE-1-containing genes in the mPFC. We also found that REST4 derepresses and upregulates the expression of some RE-1-containing genes in vivo. Importantly, transient overexpression of REST4 in the mPFC of neonatal mice produced depression-like behaviors in adults following repeated exposure to restraint stress, suggesting a crucial role of REST4 in the development of stress vulnerability. Thus, our data provide evidence suggesting that an aberrant REST-4-mediated network of genes in the early postnatal $\mathrm{mPFC}$ is involved in the increasing risk for the development of stress-related disorders, such as depression, in adulthood.

Early life stress and stress vulnerability Depression, anxiety, and posttraumatic stress disorders are known to be associated, in part, with dysregulation of the HPA axis (de Kloet et al., 2005; Müller and Holsboer, 2006). In the present study, HMS180 rats showed greater plasma corticosterone levels in response to restraint stress, which is consistent with previous reports (Francis et al., 2002; Lippmann et al., 2007; Murgatroyd et al., 2009). In addition, we found that HMS180 rats exhibited increased anxiety as adults, even in the absence of stress-inducing factors, and increased depression-like behaviors in the forced swim and sucrose preference tests after episodes of repeated restraint. Inhibition of the HPA axis response to stress is thought to protect organisms from the potentially damaging effects of long-term exposure to corticosterone (Armario et al., 2004). It should be noted that daily exposure to corticosterone and hyperreactivity of the HPA axis to repeated stress in rodents can increase depressionand anxiety-related behaviors in a stressful situation (McEwen, 2001; de Kloet et al., 2005; Uchida et al., 2008; David et al., 2009). Together, these findings suggest that the increased depression-like behaviors of stressed HMS180 rats might be associated with the increased HPA axis response to stress.

In human, early life adversity is one of the most prominent environmental factors associated with an increased risk of developing mood and anxiety disorders (Heim and Nemeroff, 2001; Gross and Hen, 2004). Previous reports indicated a direct relationship between maternal care and the development of the HPA axis and/or behaviors in rodents (Liu et al., 2000; Francis et al., 2003; Prakash et al., 2006). Early life stress is thought to act on the maturing neural circuitry to predispose an individual to a vulnerability to mood and anxiety disorders, whereas stressful events occurring in adulthood activate or amplify the expression of such symptoms (Leonardo and Hen, 2008). Supporting this notion, our data suggest that early life stress in combination with stressful events in adulthood prime the susceptibility to depression.

\section{Role of REST4-mediated gene transcription in}

stress vulnerability

REST is a transcriptional regulator with genome-wide effects important for orchestrating neuronal development (Chong et al., 1995). REST4 is generated by alternative RNA splicing of the Rest gene, is expressed specifically in the brain (Palm et al., 1998), and may function as a dominant negative or "anti-silencer" when expressed in neuronal cells (Shimojo et al., 1999). Consistent 
with these reports, our data indicate that Rest4 mRNA was expressed only in the brain, whereas Rest mRNA was ubiquitously expressed in various tissues. In addition, we found that REST4 is localized to the nucleus of mPFC neurons, suggesting that it acts as a modulator of gene expression. Furthermore, we demonstrated that REST4 enhances transcription of some of the RE-1containing genes in vivo. However, the results of expression analyses of RE1-containing genes were inconsistent between the HMS180 rats and REST4-overexpression mice. Maternal separation also affects the expression of other transcription factors, including the glucocorticoid receptor, mineralocorticoid receptor, and cAMP responsive element binding protein, in the brain (Ladd et al., 2004; Nair et al., 2007). Thus, the increased expressions of RE-1-containing genes in the HMS180 rats might be regulated not only by REST4, but also by other transcription factors. However at a minimum, the increased expressions of Glur2, Nr1, Crh, CamKIIa, Adcy5, 5htr1a, miR132, miR121 and miR-9-3 genes in HMS180 rats might be regulated by REST4, as those expressions were elevated by REST4 overexpression. It is important to note that CRH, GluR2, NR1, CaMKII $\alpha$, Adcy5 and 5-HT1A, whose mRNA levels were upregulated in this study, are suggested to be involved in stress vulnerability and anxiety (Chen et al., 1994; Stenzel-Poore et al., 1994; Liu et al., 1997; Gross et al., 2002; Mead et al., 2006; Krishnan et al., 2008; Halene et al., 2009; Hasegawa et al., 2009). More recently, augmented maternal stimulation of pups, which results in reduced stress responses (Plotsky and Meaney, 1993), was reported to enhance REST expression and subsequent reduction of $\mathrm{Crh}$ mRNA expression in the hypothalamic paraventricular nucleus (Korosi et al., 2010). Together, these data suggest that the activation of a network of RE-1-mediated genes that is induced by an increased REST4 and decreased REST during early postnatal period may account for the development of stress vulnerability in rodents.

Another finding of this study is the increased expressions of Glur2, CamKIIa, and Adcy5 mRNAs and of the precursors for Mir132, -212 and -124-1 in HMS180 rats both at P14 and adulthood. The mechanism for such a persistent effect of maternal separation on gene expression is unclear, but it may be due to epigenetic regulation. It has been suggested that epigenetic mechanisms underlie brain plasticity that requires stable modulation of gene expression (Tsankova et al., 2007; Flavell and Greenberg, 2008). Recent reports suggested that early life stress affects DNA methylation, one of the most intensely studied epigenetic mechanisms, of the glucocorticoid receptor and arginine vasopressin genes, the consequences of which are associated with altered gene expression (Weaver et al., 2004; Murgatroyd et al., 2009). Interestingly, promoters of the genes that encode GluR2, Adcy5, Mir132, and -212 all contain a CpG island (Myers et al., 1999; Vo et al., 2005; Kuang et al., 2008). In addition, REST can interact with the corepressor CoREST, which in turn, recruits histone deacetylases (Andrés et al., 1999; Grimes et al., 2000; Ballas et al., 2001). CoREST also interacts with methyl-CpG-binding protein 2 (MeCP2) and chromatin remodeling enzymes (Battaglioli et al., 2002; Lunyak et al., 2002; Shi et al., 2003; Roopra et al., 2004). Thus, REST regulates the transcription of its target genes via chromatin modifications by recruiting multiple cofactor complexes to the RE-1 site. We speculate that the persistent gene expression observed in the MPFC of HMS180 rats may be induced by such epigenetic mechanisms. However, it is still unclear how REST4 modulates the REST complexes and their functions in gene expression. Also, regulations of the expression of RE-1containing genes are complex, cell type- and developmental stage-specific. Further examinations are needed to clarify the ef- fects of early life stress on the transcription regulations of RE-1mediated gene expression.

\section{Role of mPFC in the development of stress vulnerability}

The $\mathrm{mPFC}$ plays an important role in modulating the neural circuitry that mediates the HPA axis and emotional responses to stress (Arnsten, 2009; Ulrich-Lai and Herman, 2009). Early postnatal life is a critical period for development of the mPFC (Benes et al., 2000). We found increased expressions of RE-1-containing miRNAs in the mPFC of HMS180 rats, and some of their expressions were regulated by REST4 in vivo. This is the first report showing the altered expressions of miRNAs by early life stress and REST4. Importantly, miRNAs are strongly suggested to be involved in neuronal functions, including brain development and plasticity (Vo et al., 2005; Conaco et al., 2006; Kosik, 2006; Rajasethupathy et al., 2009). REST-controlled miRNAs (e.g., Mir132, -124) are already known to regulate neuronal morphogenesis, differentiation, and synaptic plasticity (Vo et al., 2005; Conaco et al., 2006; Rajasethupathy et al., 2009). It is interesting to note that early life stress results in a decrease in dendritic length (Pascual et al., 2007), a decrease in the number of astrocytes (Musholt et al., 2009), abnormally high synaptic density (Ovtscharoff and Braun, 2001), and an attenuated basal neuronal activity (Stevenson et al., 2008) within the mPFC. More recently, Goodfellow et al. (2009) reported an increased 5-HT1Amediated outward current and an increased expression of $5 \mathrm{htr} 1 \mathrm{a}$ mRNA in the mPFC during postnatal development of maternally separated rats, the latter of which was replicated by our present expression analyses. Based on these data, we propose that an aberrant RE-1-mediated network of genes may affect structural and synaptic plasticity within the mPFC of developing animals, which then lead to the stress vulnerability in adulthood.

\section{Conclusions}

Our results support to concept that early adverse life events can modulate the neuroendocrine and behavioral responses to stress. More importantly, our data suggest that the activation of a REST4-mediated gene network in the MPFC at an early stage of postnatal development may enhance and contribute to mood and anxiety disorders in response to chronic stressful life events during adulthood. Similarities between effects in mice and rats support this conclusion.

\section{References}

American Psychiatric Association (1994) Diagnostic and Statistical Manual of Mental Disorders, Ed 4. Washington, DC: American Psychiatric Association.

Andrés ME, Burger C, Peral-Rubio MJ, Battaglioli E, Anderson ME, Grimes J, Dallman J, Ballas N, Mandel G (1999) CoREST: a functional corepressor required for regulation of neural-specific gene expression. Proc Natl Acad Sci U S A 96:9873-9878.

Armario A, Martí O, Vallès A, Dal-Zotto S, Ons S (2004) Long-term effects of a single exposure to immobilization on the hypothalamic-pituitaryadrenal axis: neurobiologic mechanisms. Ann NY Acad Sci 1018:162-172.

Arnsten AF (2009) Stress signalling pathways that impair prefrontal cortex structure and function. Nat Rev Neurosci 10:410-422.

Ballas N, Battaglioli E, Atouf F, Andres ME, Chenoweth J, Anderson ME, Burger C, Moniwa M, Davie JR, Bowers WJ, Federoff HJ, Rose DW, Rosenfeld MG, Brehm P, Mandel G (2001) Regulation of neuronal traits by a novel transcriptional complex. Neuron 31:353-365.

Battaglioli E, Andrés ME, Rose DW, Chenoweth JG, Rosenfeld MG, Anderson ME, Mandel G (2002) REST repression of neuronal genes requires components of the hSWI.SNF complex. J Biol Chem 277:41038-41045.

Benes FM, Taylor JB, Cunningham MC (2000) Convergence and plasticity of monoaminergic systems in the medial prefrontal cortex during the 
postnatal period: implications for the development of psychopathology. Cereb Cortex 10:1014-1027.

Chen C, Rainnie DG, Greene RW, Tonegawa S (1994) Abnormal fear response and aggressive behavior in mutant mice deficient for alphacalcium-calmodulin kinase II. Science 266:291-294.

Chong JA, Tapia-Ramírez J, Kim S, Toledo-Aral JJ, Zheng Y, Boutros MC, Altshuller YM, Frohman MA, Kraner SD, Mandel G (1995) REST: a mammalian silencer protein that restricts sodium channel gene expression to neurons. Cell 80:949-957.

Conaco C, Otto S, Han JJ, Mandel G (2006) Reciprocal actions of REST and a microRNA promote neuronal identity. Proc Natl Acad Sci US A 103:2422-2427.

David DJ, Samuels BA, Rainer Q, Wang JW, Marsteller D, Mendez I, Drew M, Craig DA, Guiard BP, Guilloux JP, Artymyshyn RP, Gardier AM, Gerald C, Antonijevic IA, Leonardo ED, Hen R (2009) Neurogenesisdependent and -independent effects of fluoxetine in an animal model of anxiety/depression. Neuron 62:479-493.

de Kloet ER, Joëls M, Holsboer F (2005) Stress and the brain: from adaptation to disease. Nat Rev Neurosci 6:463-475.

Duman RS, Monteggia LM (2006) A neurotrophic model for stress-related mood disorders. Biol Psychiatry 59:1116-1127.

Flavell SW, Greenberg ME (2008) Signaling mechanisms linking neuronal activity to gene expression and plasticity of the nervous system. Annu Rev Neurosci 31:563-590.

Francis DD, Diorio J, Plotsky PM, Meaney MJ (2002) Environmental enrichment reverses the effects of maternal separation on stress reactivity. J Neurosci 22:7840-7843.

Francis DD, Szegda K, Campbell G, Martin WD, Insel TR (2003) Epigenetic sources of behavioral differences in mice. Nat Neurosci 6:445-446.

Goodfellow NM, Benekareddy M, Vaidya VA, Lambe EK (2009) Layer II/III of the prefrontal cortex: Inhibition by the serotonin 5-HT1A receptor in development and stress. J Neurosci 29:10094-10103.

Grimes JA, Nielsen SJ, Battaglioli E, Miska EA, Speh JC, Berry DL, Atouf F, Holdener BC, Mandel G, Kouzarides T (2000) The co-repressor $\mathrm{mSin} 3 \mathrm{~A}$ is a functional component of the REST-CoREST repressor complex. J Biol Chem 275:9461-9467.

Gross C, Hen R (2004) The developmental origins of anxiety. Nat Rev Neurosci 5:545-552.

Gross C, Zhuang X, Stark K, Ramboz S, Oosting R, Kirby L, Santarelli L, Beck S, Hen R (2002) Serotonin 1A receptor acts during development to establish normal anxiety-like behaviour in the adult. Nature 416:396-400.

Halene TB, Ehrlichman RS, Liang Y, Christian EP, Jonak GJ, Gur TL, Blendy JA, Dow HC, Brodkin ES, Schneider F, Gur RC, Siegel SJ (2009) Assessment of NMDA receptor NR1 subunit hypofunction in mice as a model for schizophrenia. Genes Brain Behav 8:661-675.

Hasegawa S, Furuichi T, Yoshida T, Endoh K, Kato K, Sado M, Maeda R, Kitamoto A, Miyao T, Suzuki R, Homma S, Masushige S, Kajii Y, Kida S (2009) Transgenic up-regulation of alpha-CaMKII in forebrain leads to increased anxiety-like behaviors and aggression. Mol Brain 2:6.

Heim C, Nemeroff CB (2001) The role of childhood trauma in the neurobiology of mood and anxiety disorders: preclinical and clinical studies. Biol Psychiatry 49:1023-1039.

Korosi A, Shanabrough M, McClelland S, Liu ZW, Borok E, Gao XB, Horvath TL, Baram TZ (2010) Early-life experience reduces excitation to stressresponsive hypothalamic neurons and reprograms the expression of corticotropin-releasing hormone. J Neurosci 30:703-713.

Kosik KS (2006) The neuronal microRNA system. Nat Rev Neurosci 7:911-920.

Krishnan V, Graham A, Mazei-Robison MS, Lagace DC, Kim KS, Birnbaum S, Eisch AJ, Han PL, Storm DR, Zachariou V, Nestler EJ (2008) Calcium-sensitive adenylyl cyclases in depression and anxiety: behavioral and biochemical consequences of isoform targeting. Biol Psychiatry 64:336-343.

Kuang SQ, Tong WG, Yang H, Lin W, Lee MK, Fang ZH, Wei Y, Jelinek J, Issa JP, Garcia-Manero G (2008) Genome-wide identification of aberrantly methylated promoter associated CpG islands in acute lymphocytic leukemia. Leukemia 22:1529-1538.

Ladd CO, Huot RL, Thrivikraman KV, Nemeroff CB, Plotsky PM (2004) Long-term adaptations in glucocorticoid receptor and mineralocorticoid receptor mRNA and negative feedback on the hypothalamo-pituitaryadrenal axis following neonatal maternal separation. Biol Psychiatry $55: 367-375$.
Leonardo ED, Hen R (2008) Anxiety as a developmental disorder. Neuropsychopharmacology 33:134-140.

Lippmann M, Bress A, Nemeroff CB, Plotsky PM, Monteggia LM (2007) Long-term behavioural and molecular alterations associated with maternal separation in rats. Eur J Neurosci 25:3091-3098.

Liu D, Diorio J, Tannenbaum B, Caldji C, Francis D, Freedman A, Sharma S, Pearson D, Plotsky PM, Meaney MJ (1997) Maternal care, hippocampal glucocorticoid receptors, and hypothalamic-pituitary-adrenal responses to stress. Science 277:1659-1662.

Liu D, Diorio J, Day JC, Francis DD, Meaney MJ (2000) Maternal care, hippocampal synaptogenesis and cognitive development in rats. Nat Neurosci 3:799-806.

Lunyak VV, Burgess R, Prefontaine GG, Nelson C, Sze SH, Chenoweth J, Schwartz P, Pevzner PA, Glass C, Mandel G, Rosenfeld MG (2002) Corepressor-dependent silencing of chromosomal regions encoding neuronal genes. Science 298:1747-1752.

McEwen BS (2001) Plasticity of the hippocampus: adaptation to chronic stress and allostatic load. Ann N Y Acad Sci 933:265-277.

Mead AN, Morris HV, Dixon CI, Rulten SL, Mayne LV, Zamanillo D, Stephens DN (2006) AMPA receptor GluR2, but not GluR1, subunit deletion impairs emotional response conditioning in mice. Behav Neurosci 120:241-248.

Meaney MJ (2001) Maternal care, gene expression, and the transmission of individual differences in stress reactivity across generations. Annu Rev Neurosci 24:1161-1192.

Müller MB, Holsboer F (2006) Mice with mutations in the HPA-system as models for symptoms of depression. Biol Psychiatry 59:1104-1115.

Murgatroyd C, Patchev AV, Wu Y, Micale V, Bockmühl Y, Fischer D, Holsboer F, Wotjak CT, Almeida OF, Spengler D (2009) Dynamic DNA methylation programs persistent adverse effects of early-life stress. Nat Neurosci 12:1559-1566.

Musholt K, Cirillo G, Cavaliere C, Rosaria Bianco M, Bock J, Helmeke C, Braun K, Papa M (2009) Neonatal separation stress reduces glial fibrillary acidic protein- and S100beta-immunoreactive astrocytes in the rat medial precentral cortex. Dev Neurobiol 69:203-211.

Myers SJ, Dingledine R, Borges K (1999) Genetic regulation of glutamate receptor ion channels. Annu Rev Pharmacol Toxicol 39:221-241.

Nair A, Vadodaria KC, Banerjee SB, Benekareddy M, Dias BG, Duman RS, Vaidya VA (2007) Stressor-specific regulation of distinct brainderived neurotrophic factor transcripts cyclic AMP response elementbinding protein expression in the postnatal and adult rat hippocampus. Neuropsychopharmacology 32:1504-1519.

Otto SJ, McCorkle SR, Hover J, Conaco C, Han JJ, Impey S, Yochum GS, Dunn JJ, Goodman RH, Mandel G (2007) A new binding motif for the transcriptional repressor REST uncovers large gene networks devoted to neuronal functions. J Neurosci 27:6729-6739.

Ovtscharoff W Jr, Braun K (2001) Maternal separation and social isolation modulate the postnatal development of synaptic composition in the infralimbic cortex of Octodon degus. Neuroscience 104:33-40.

Palm K, Belluardo N, Metsis M, Timmusk T (1998) Neuronal expression of zinc finger transcription factor REST/NRSF/XBR gene. J Neurosci 18:1280-1296.

Pascual R, Zamora-Leon P, Catalán-Ahumada M, Valero-Cabré A (2007) Early social isolation decreases the expression of calbindin D-28k and dendritic branching in the medial prefrontal cortex of the rat. Int J Neurosci 117:465-476.

Plotsky PM, Meaney MJ (1993) Early, postnatal experience alters hypothalamic corticotropin-releasing factor (CRF) mRNA, median eminence CRF content and stress-induced release in adult rats. Brain Res Mol Brain Res 18:195-200.

Porsolt RD, Bertin A, Jalfre M (1977) Behavioral despair in mice: a primary screening test for antidepressants. Arch Int Pharmacodyn Ther 229:327-336.

Prakash P, Merali Z, Kolajova M, Tannenbaum BM, Anisman H (2006) Maternal factors and monoamine changes in stress-resilient and susceptible mice: cross-fostering effects. Brain Res 1111:122-133.

Rajasethupathy P, Fiumara F, Sheridan R, Betel D, Puthanveettil SV, Russo JJ, Sander C, Tuschl T, Kandel E (2009) Characterization of small RNAs in Aplysia reveals a role for miR-124 in constraining synaptic plasticity through CREB. Neuron 63:803-817.

Roceri M, Hendriks W, Racagni G, Ellenbroek BA, Riva MA (2002) Early 
maternal deprivation reduces the expression of BDNF and NMDA receptor subunits in rat hippocampus. Mol Psychiatry 7:609-616.

Roopra A, Qazi R, Schoenike B, Daley TJ, Morrison JF (2004) Localized domains of G9a-mediated histone methylation are required for silencing of neuronal genes. Mol Cell 14:727-738.

Schoenherr CJ, Anderson DJ (1995) The neuron-restrictive silencer factor (NRSF): a coordinate repressor of multiple neuron-specific genes. Science 267:1360-1363.

Shi Y, Sawada J, Sui G, Affar el B, Whetstine JR, Lan F, Ogawa H, Luke MP, Nakatani Y, Shi Y (2003) Coordinated histone modifications mediated by a CtBP co-repressor complex. Nature 422:735-738.

Shimojo M, Paquette AJ, Anderson DJ, Hersh LB (1999) Protein kinase A regulates cholinergic gene expression in PC12 cells: REST4 silences the silencing activity of neuron-restrictive silencer factor/REST. Mol Cell Biol 19:6788-6795.

Stenzel-Poore MP, Heinrichs SC, Rivest S, Koob GF, Vale WW (1994) Overproduction of corticotropin-releasing factor in transgenic mice: a genetic model of anxiogenic behavior. J Neurosci 14:2579-2584.

Stevenson CW, Marsden CA, Mason R (2008) Early life stress causes FG7142-induced corticolimbic dysfunction in adulthood. Brain Res 1193: 43-50.

Tapia-Ramírez J, Eggen BJ, Peral-Rubio MJ, Toledo-Aral JJ, Mandel G (1997) A single zinc finger motif in the silencing factor REST represses the neural-specific type II sodium channel promoter. Proc Natl Acad Sci U S A 94:1177-1182.

Tsankova N, Renthal W, Kumar A, Nestler EJ (2007) Epigenetic regulation in psychiatric disorders. Nat Rev Neurosci 8:355-367.
Uchida S, Kitamoto A, Umeeda H, Nakagawa N, Masushige S, Kida S (2005) Chronic reduction in dietary tryptophan leads to changes in the emotional response to stress in mice. J Nutr Sci Vitaminol (Tokyo) 51: 175-181.

Uchida S, Sakai S, Furuichi T, Hosoda H, Toyota K, Ishii T, Kitamoto A, Sekine M, Koike K, Masushige S, Murphy G, Silva AJ, Kida S (2006) Tight regulation of transgene expression by tetracycline-dependent activator and repressor in brain. Genes Brain Behav 5:96-106.

Uchida S, Nishida A, Hara K, Kamemoto T, Suetsugi M, Fujimoto M, Watanuki T, Wakabayashi Y, Otsuki K, McEwen BS, Watanabe Y (2008) Characterization of the vulnerability to repeated stress in Fischer 344 rats possible involvement of microRNA-mediated down-regulation of the glucocorticoid receptor. Eur J Neurosci 27:2250-2261.

Uchida S, Hara K, Kobayashi A, Otsuki K, Teruyuki, Hobara T, Yamagata H, Watanabe Y (2010) Maternal and genetic factors in stress-resilient and -vulnerable rats: A cross-fostering study. Brain Res 1316:43-50.

Ulrich-Lai YM, Herman JP (2009) Neural regulation of endocrine and autonomic stress responses. Nat Rev Neurosci 10:397-409.

Vo N, Klein ME, Varlamova O, Keller DM, Yamamoto T, Goodman RH, Impey S (2005) A cAMP-response element binding protein-induced microRNA regulates neuronal morphogenesis. Proc Natl Acad Sci U S A 102:16426-16431.

Weaver IC, Cervoni N, Champagne FA, D’Alessio AC, Sharma S, Seckl JR, Dymov S, Szyf M, Meaney MJ (2004) Epigenetic programming by maternal behavior. Nat Neurosci 7:847-854.

Zimmerman M, Chelminski I, McDermut W (2002) Major depressive disorder and axis I diagnostic comorbidity. J Clin Psychiatry 63:187-193. 